\title{
Polemoniaceae endémicas del Perú
}

\author{
Blanca León ${ }^{1,2}$
}

${ }^{1}$ Museo de Historia Natural, Av. Arenales 1256, Aptdo. 14-0434, Lima 14, Perú

2 Plant Resources Center, University of Texas at Austin, Austin TX 78712 EE.UU.

blanca.leon@mail.utexas.edu

\section{Resumen}

La familia Polemoniaceae es reconocida en el Perú por presentar cinco géneros y 24 especies (Brako \& Zarucchi, 1993; Ulloa Ulloa et al., 2004), hierbas, arbustos y bejucos. En este trabajo reconocemos nueve especies endémicas en cuatro géneros. Un género, Huthia, es endémico del Perú. El género más rico en especies es Cantua, el cual requiere de una evaluación taxonómica. Las especies endémicas se encuentran principalmente en las regiones Mesoandina y Matorral Desértico, desde los 1900 m hasta los $3600 \mathrm{~m}$ de altitud. Aparentemente, sólo una especie endémica ha sido registrada dentro del Sistema Nacional de Áreas Naturales Protegidas por el Estado.

Palabras claves: Polemoniaceae, Cantua, Huthia, Perú, endemismo, plantas endémicas.

\section{Abstract}

The Polemoniaceae are represented in Peru by five genera and 24 species (Brako \& Zarucchi, 1993; Ulloa Ulloa et al., 2004), between herbs, shrubs and vines. Here we recognize nine endemic taxa in four genera. One genus, Huthia, is endemic to Peru. Cantua is the genus with the largest number of endemic species, and it requires a modern taxonomic evaluation. Endemic species in this family are found mainly in Mesoandean and Desert Shrubland regions, from $1900 \mathrm{~m}$ to $3600 \mathrm{~m}$ elevation. Apparently, only one species has been recorded in the Peruvian System of Protected Natural Areas.

Keywords: Polemoniaceae, Cantua, Huthia, Peru, endemism, endemic plants.

\section{Cantua candelilla Brand}

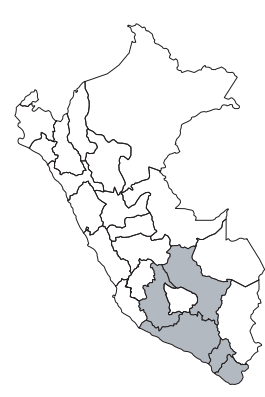

\section{LC}

Publicación: Pflanzenr. IV, 250 (Heft 27): 22. 1907.

Colección tipo: A. Weberbauer 1428

Herbarios: B.

Nombre común: Desconocido.

Registro departamental: AR, AY, CU, MO, TA.

Regiones Ecológicas: MA, PSH; 2800$3600 \mathrm{~m}$.

SINANPE: Sin registro.

Herbarios peruanos: HUSA (2), HUT (3).

Observaciones: Arbusto conocido de varias localidades en el centro y sur del país, donde crece en matorrales de valles interandinos. El ejemplar tipo fue recolectado en la cuenca alta del Chili. El género requiere de una revisión taxonómica moderna.

\section{Cantua cordata Juss.}

\section{NE}

Publicación: Ann. Mus. Natl. Hist. Nat. 3: 119. 1804.

Colección tipo: Jussieu s.n.

Herbarios: P.

Nombre común: Desconocido.

Registro departamental: Sin datos.

Regiones Ecológicas: Sin datos; altitud desconocida.

SINANPE: Sin registro.

Herbarios peruanos: Ninguno.

Observaciones: Esta especie fue recolectada en el siglo XVIII, aparentemente en el país, desconociéndose la procedencia exacta.

\section{Cantua longifolia Brand}

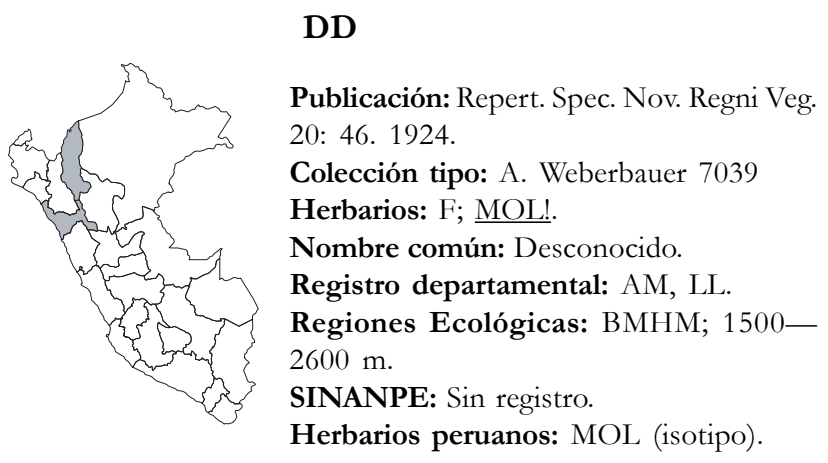

Observaciones: Arbusto conocido de unas pocas poblaciones dispersas. Fue recolectado originalmente en 1914, de la cuenca alta del Mishollo, un afluente del Huallaga, al sur del área que ocupa el Parque Nacional Río Abiseo, pero no se conoce de este Parque. Los ambientes naturales de la cuenca del Mishollo están afectados por la actividad agrícola; sin embargo, no existe una evaluación florística detallada de esa cuenca ni de la situación de conservación de esos ambientes.

\section{Cantua ovata Cav.}

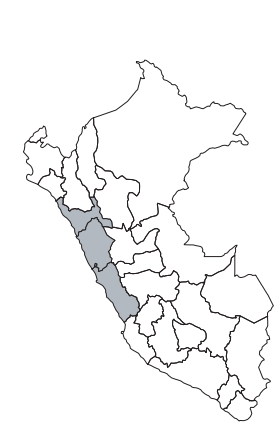

\section{DD}

Publicación: Icon. 4: 43, t. 363. 1797.

Colección tipo: L. Née s.n.

Herbarios: MA.

Nombre común: Desconocido.

Registro departamental: AN, LI, LL.

Regiones Ecológicas: MA; altitud desconocida.

SINANPE: Sin registro.

Herbarios peruanos: Ninguno.

Observaciones: Esta especie fue reconocida por Infantes (1962), pero no por Gibson (1967), quien la consideró en la sinonimia de Cantua buxifolia. Fue descrita de una planta recolectada en el siglo XVIII, de la cuenca del Chillón. El género necesita revisión taxonómica. 


\section{Cantua tomentosa Cav.}

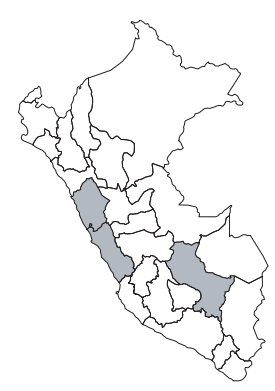

\section{DD}

Publicación: Icon. 4: 43, t. 364. 1797. Colección tipo: A.J. Cavanilles s.n.

Herbarios: MA.

Nombre común: Desconocido.

Registro departamental: AN, CU, LI. Regiones Ecológicas: MA; altitud desconocida.

SINANPE: Sin registro.

Herbarios peruanos: Ninguno.

Observaciones: Esta especie fue reconocida por Infantes (1962), pero no por Gibson (1967), quien consideró en la sinonimia de Cantua buxifolia. El género necesita revisión taxonómica.

\section{Cobaea flava Prather}

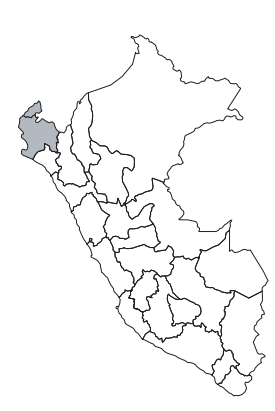

\section{NT}

Publicación: Brittonia 48(1): 114-116, f. 1 a-d. 1996.

Colección tipo: A. Weberbauer 6397

Herbarios: F, GH, US.

Nombre común: Desconocido.

Registro departamental: PI, TU.

Regiones Ecológicas: DCT, MDE; 600$1500 \mathrm{~m}$.

SINANPE: PNCAm

Herbarios peruanos: Ninguno.

Observaciones: Bejuco conocido de varias localidades, al parecer, solamente en el noroocidente del país, en las cuencas del Quiróz, Yapatera y Pasmalca. Podría estar representada en la flora ecuatoriana.

\section{Gilia lomensis V.E. Grant}

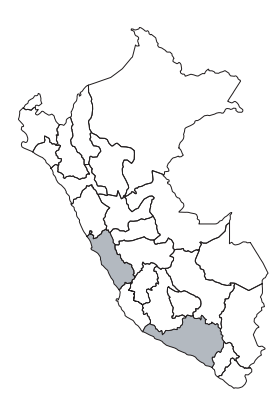

\section{EN, B1ab(iii)}

Publicación: Aliso 6(2): 72, f. 4. 1966. Colección tipo: O. Velarde \& M. Reiche ex V. Grant 2244

Herbarios: RSA.

Nombre común: Desconocido.

Registro departamental: AR, LI.

Regiones Ecológicas: DST; 80-125 m. SINANPE: Sin registro.

Herbarios peruanos: Ninguno.

Observaciones: Hierba anual, conocida de unas pocas localidades dispersas en la costa del centro y sur del país. Esta especie fue descrita de plantas en cultivo, provenientes de semillas recolectadas en uno de los cerros de las «Lomas de Amancaes», la cual está deteriorada por la expansión urbana y a pesar de las visitas botánicas repetidas desde 2001 no ha sido reubicada ahí (A. Cano, com. pers.).

\section{Huthia coerulea Brand}

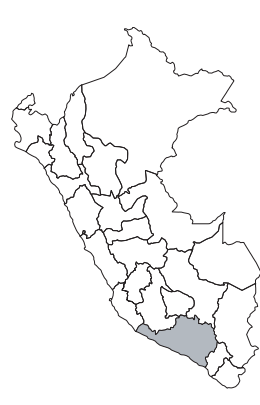

DD

Publicación: Bot. Jahrb. Syst. 42: 175. 1908.

Colección tipo: A. Weberbauer 4837

Herbarios:

Nombre común: Desconocido.

Registro departamental: AR.

Regiones Ecológicas: MDE, MA; 2200$3200 \mathrm{~m}$.

SINANPE: Sin registro.

Herbarios peruanos: Ninguno.

Observaciones: Especie arbustiva conocida de unas pocas localidades vecinas, en la cuenca alta del Chili, donde ocupa matorrales semixéricos. Esta es una de las dos especies de este género endémico. Fue descrito de una planta recolectada en 1905. Se desconoce el estado actual de sus poblaciones.

\section{Huthia longiflora Brand}

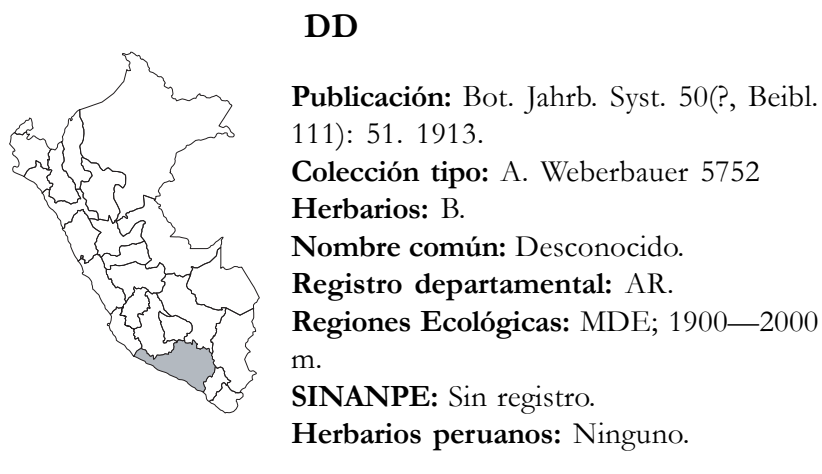

Observaciones: Arbusto conocido, al parecer, de una sola localidad, donde fue recolectado en 1911, entre la cuenca del Lomas y del Yauca. Esta es una de las dos especies de este género endémico. Se desconoce el estado actual de sus poblaciones. 